\title{
Arquitetura escolar na cidade de Feira de Santana - 1910 a 1940
}

\author{
Rebeca Laíse Santos Lima ${ }^{1}$; Ione Celeste Jesus de Sousa ${ }^{2}$ \\ 1. Bolsista PROBIC/UEFS, Graduanda em Licenciatura em História, Universidade Estadual \\ de Feira de Santana, e-mail: rebecalaise@ gmail.com \\ 2. Orientador, Departamento de Ciências Humanas e Filosofia, Universidade Estadual de \\ Feira de Santana, e-mail: ionecjs@gmail.com
}

PALAVRAS-CHAVE: Arquitetura; Feira de Santana; Educação.

\section{Introdução}

Essa proposta de trabalho tem por objetivo analisar a escolarização feirense através da arquitetura escolar da cidade de Feira de Santana, desde a construção dos prédios do Grupo Escolar (1912) e das Escolas Reunidas (1917 e 1918) até o período da instalação e funcionamento de cursos de cunho profissional, entre as décadas de 1920 e 1940, quais sejam, o da Escola Normal de Feira de Santana (prédio adaptado em 1927) e dos cursos secundário e/ ou comercial, caso do Ginásio Santanopólis. O interesse é acompanhar as mudanças na arquitetura escolar como expressões de novas ideias pedagógicas que nortearam o projeto educacional do estado republicano.

Faria Filho (2001) argumenta que os grupos escolares eram considerados palácios da modernidade, instrumentos de progresso e mudança, ao contrário das escolas isoladas tidas como símbolo da continuidade de um passado de miséria e atraso da educação, já que funcionavam locais inadequados, sem o material pedagógico: os pardieiros.

O primeiro prédio estritamente escolar na cidade de Feira de Santana com esta aura republicana (OLIVEIRA, 2016) foi o do grupo escolar, fundado em 1914. A partir de 1916 recebeu a denominação de Grupo Escolar Jose Joaquim Seabra, em homenagem ao então presidente do estado da Bahia. O prédio começou a ser construído no governo Coronel Bernardino Silva Bahia (de 1912 a 1915), sendo entregue no governo do Coronel Agostinho no ano de 1916. Este intendente municipal dois anos depois construiu os prédios para instalar as escolas Maria Quitéria (1917) e João Florêncio (1918) (OLIVEIRA, 2016) situados em locais centrais da cidade: Avenida Senhor dos Passos e Praça Agostinho Froes da Mota, antiga rua dos Remedios. A escola Maria Quiteria continua funcionando até o atual momento no mesmo local, tendo o prédio sofrido poucas intervenções arquitetônicas.

Segundo as pesquisas de Faria Filho (2000) e de Bencosta (2005), a construção desses palacetes educacionais da primeira republica tinha característica uma arquitetura sofisticada, no intuito de se contrapor às antigas escolas imperiais, que funcionavam nas mesmas casas onde os professores residiam. A suntuosidade dos prédios serviria para evidenciar o progresso e as novas concepções de organização escolar.

Quanto aos grupos escolares passaram a reunir várias séries num único prédio Bencosta (2005) destaca a preocupação das administrações com o urbano enquanto espaço privilegiado para a sua edificação: capitais e cidades prósperas. Funcionavam como signo dos ideais republicanos, uma gramática discursiva arquitetônica que enaltecia o novo regime (SILVA, 2016).

O interesse desta pesquisa no campo da História Socio-Cultural da Educação é analisar o processo de escolarização no acompanhar as mudanças na arquitetura escolar como expressões de novas ideias pedagógicas, especialmente as questões de higiene escolar marcada pelas ideias eugenistas do início do século XX, assim como as concepções de metodologia do ensino. 


\section{MATERIAL E MÉTODOS OU METODOLOGIA (ou equivalente)}

Pesquisar nas fontes da burocracia da intendência feirense do período de 1910-1940 os ofícios, relatórios, Atas da Câmara, livros fazendários e de escrituração urbana - assim como nos periódicos feirenses, as marcas da arquitetura escolar feirense. Teoricamente a perspectiva é da História Social-Cultural que toma as construções físicas como aspectos da Cultura Material e das representações dos sujeitos. A pesquisa especifica esta inserida no Campo Temático da História da Educação, utilizando o conceito de Cultura Escolar para investigar a construção de materiais e métodos de escolarização, dentre estes os próprios prédios construídos a partir de noções de higiene escolar e métodos de ensino historicamente constituídos.

\section{RESULTADOS ALCANÇADOS E DISCUSSÃO}

O projeto de pesquisa com o título de "Arquitetura na cidade de Feira de Santana1912/1950" analisa no processo de escolarização desta cidade as mudanças na arquitetura escolar como expressões de ideias pedagógicas republicanas (FARIA FILHO: 2000), especialmente as questões de higiene escolares marcadas pelas ideias eugenistas do início do século XX (BENCOSTA: 2000). De acordo com a revisão bibliográfica realizada durante a pesquisa, a arquitetura dos edifícios escolares se constitui num objeto repleto de possibilidades. Souza (2014) argumenta que são (...) portadores de múltiplos significados, a arquitetura e o espaço escolares tem se constituído nos últimos anos em promissoras vertentes de investigação sobre a cultura escolar" (2014, p.8). Explicitamente sobre esta cidade, Ione Sousa (2012) afirma sobre a presença da Escola Normal de Feira de Santana:

"Além do estritamente relativo a vida cotidiana intraportões da Escola Normal, apresento seus entrelaçamentos com a modernização urbana da cidade de Feira de Santana, nos anos 1920/40, com a abertura de novas ruas e avenidas, que alimentou a emergência de novas sociabilidades públicas para as normalistas e outras moças de escola, a exemplo dos passeios pela rua Conselheiro Franco e próximas" (SOUSA, 2012, p.125).

Durante o período pesquisado (1912 - 1940), foram analisados a arquitetura de quatro prédios escolares que se destacaram: o Grupo Escolar José Joaquim Seabra, que era o então presidente do estado, foi inaugurado na Intendência do Coronel Agostinho Fróes da Motta, um dos personagens mais importantes da Primeira República/pós-abolição de Feira de Santana; o Ginásio Santanopólis, local onde se formaram oito prefeitos de Feira de Santana, inaugurado em 1933 permaneceu em funcionamento até 1984; a escola João Florêncio, que era uma escola inicialmente só para meninos; e a Escola Maria Quitéria, a única cujo prédio continua funcionando como escola desde sua fundação, em 1917, completara assim em 2017 os seus 100 anos de funcionamento.

A pesquisa permite afirmar que estes quatro prédios buscaram cumprir as funções escoares e simbólicas destacadas na historiografia existente: se concentravam em locais centrais da cidade e de fácil acesso. Serviram como instrumentos para a criação de novos espaços sociais, com espaços amplos, bem construídos, ricos em detalhes nas suas fachadas e bem localizados. Diferiam das antigas casas de aula que vigoraram durante o império: casas alugadas, salas alugadas ou na sua maioria nas casas dos professores, situadas em paróquias de forma improvisada, em locais ermos e de difícil acesso. Eram lugares insalubres e geralmente mal iluminados, pouco higiênicos. Seu mobiliário e materiais didáticos eram precários como indicam Sousa (2006) e Silva (2007) para a Bahia provincial. 
Destacamos que a construção destes edifícios escolares, que tinham como característica uma arquitetura mais sofisticada e suntuosa, condiziam com o projeto ideal educacional republicano que tinha por anseio levar o progresso e modernidade para o interior do país, com o discurso de preocupação com o analfabetismo, no intuito que o país que estava em construção fosse civilizado. Neste, a educação teria o papel fundamental de formar e forjar novos sujeitos sociais através também da educação (SOUSA: 2001).

\section{CONSIDERAÇOES FINAIS (ou conclusão)}

Os resultados obtidos na pesquisa indicam que a arquitetura escolar em Feira de Santana no período delimitado se constituiu num marco urbano, em consonância com outros de várias cidades brasileiras, parte de um ideal republicano do início do século XX. A pesquisa também contribuiu para identificar que a cidade de Feira de Santana teve um papel importante no cenário político baiano ao conseguir instalar aqui os grupos escolares importantes para a modernização do sistema de ensino no interior. Além disto, esta investigação pode contribuir para diversidade de temas na construção da memória de Feira de Santana.

\section{REFERÊNCIAS}

1. BENCOSTA, Marcus Levy. História da Educação, Arquitetura e Espaço Escolar. SP: Cortez; 2005.

2. BENCOSTA, M. L. A. A noção da cultura material escolar em debate no campo da investigação da História da Educação. In: César Augusto Castro e Samuel Luis Velásquez Castellanos. (Org.). A Escola e seus artefatos culturais. 1 ed. São Luiz: EDUFMA, 2013, v.1, p. 21-34.

3. BENCOSTA, M. L. A. "Grupos Escolares no Brasil: um novo modelo de escola primaria". In: STEPHANOU, M e BASTOS, M.HC. (orgs.) História e memorias da educação no Brasil. Vol. III. PETROPOLIS: Editora Vozes, 2005.

4. FARIA FILHO, L. M. de. Dos pardieiros aos palácios. Cultura Escolar e urbana em Belo Horizonte na Primeira República. Passo Fundo: Editora da UPF, 2000.

5. OLIVEIRA, Daiane Silva. INSTRUÇÃO DE POBRES E NEGROS EM FEIRA DE SANTANA: As Escolas do Professor Primário Geminiano Alves da Costa (1890 a 1920). Feira de Santana, UEFS- PPGH-Mestrado em História, 2016. Orientação prof ${ }^{a}$ Dr $^{\text {a }}$ Ione Sousa. 6. ROCHA \& BARROS, Grupos Escolares Cultura Escolar Primaria e Escolarização da Infância no Brasil 1839 - 1917. A Educação Primária Baiana: Grupos Escolares na Penumba.

7. SOUSA, Ione \& CRUZ, Antônio Roberto (orgs). Escolas Normais da Bahia: olhares e abordagens. Feira de Santana: UEFS Editora; 2013.

8. SOUSA, Ione. Garotas tricolores, Deusas fardadas: as normalistas em Feira de Santana. SP: EDUC/PUC. 2002 